\title{
Influence of body mass index on the response to asthma controller agents
}

\author{
M. Peters-Golden*, A. Swern\# , S.S. Bird", C.M. Hustad ", E. Grant" and J.M. Edelman
}

ABSTRACT: The incidence of asthma has been positively associated with obesity. Asthma comprises diverse "phenotypes" reflecting heterogeneity in a number of characteristics, including response to therapy. The present authors examined whether body mass index (BMI) influenced the response to placebo, as well as to two asthma controller medications.

A post hoc analysis was performed, pooling data from four double-blind, placebo-controlled studies randomising 3,073 moderate asthmatic adults to montelukast $(n=1,439)$, beclomethasone $(n=894)$ or placebo $(n=740)$. The primary end point was asthma control days; other end points were forced expiratory volume in one second, $\beta$-agonist use and nocturnal awakening. Analyses were conducted using BMI classification into normal $\left(<25.0 \mathrm{~kg} \cdot \mathrm{m}^{-2} ; \mathbf{5 2} \%\right.$ of patients), overweight $\left(25-29.9 \mathrm{~kg} \cdot \mathrm{m}^{-2} ; 32 \%\right)$ and obese $\left(\geqslant 30.0 \mathrm{~kg} \cdot \mathrm{m}^{-2} ; 16 \%\right)$ categories, as well as $\mathrm{BMI}$ as a continuous variable.

The treatment groups were balanced for BMI, demographic characteristics and parameters of asthma control. The placebo response for all end points was generally lower with increasing BMI. Similarly, the response to the inhaled corticosteroid decreased, whereas the response to the leukotriene antagonist remained stable.

In conclusion, post hoc data from the present study suggested that body mass index may influence the natural history of asthma control (as reflected by response to placebo) and may differentially influence response to the two active agents, warranting explicit testing in future prospective studies.

KEYWORDS: Asthma, beclomethasone, body mass index, inhaled corticosteroid, leukotriene antagonist, montelukast

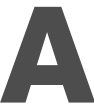
sthma encompasses multiple "phenotypes". As is the case for characteristics such as clinical presentation, physiological findings and the nature of airway inflammation [1], it is also clear that individual patients vary in their responsiveness to medications [2]. This phenomenon is perhaps most widely appreciated for the recently introduced class of antileukotriene (LT) agents, whose efficacy rates have been reported to range from $\sim 40-70 \%$, depending on the outcome variable examined [3-6]. It is less well appreciated that significant numbers of asthma patients are also refractory to treatment with inhaled corticosteroids $[3,7]$ and $\beta$-adrenergic agonists [8].

Variations in responsiveness to asthma medications are potentially explained by genetically determined differences in expression of drug target molecules [9]. Although polymorphisms or splice variants in genes encoding LT biosynthetic enzymes [10,11] and receptors [12], as well as glucocorticoid receptors [13], have been reported, these are, thus far, either of uncertain functional significance or can account for only a small proportion of variation in therapeutic responsiveness to asthma controller medications [1418]. Although recent evidence suggests that smoking may influence responses to inhaled corticosteroids [19], little else is known about the influence of acquired factors on responses to asthma therapy.

Just as the incidence of asthma has increased in the USA and other developed nations over the last 20 yrs [20], so has that of obesity [21]. In fact, a nexus of these two epidemics exists [22], as shown by the recognition from a number of epidemiological studies (although not all studies [22]) that obesity is associated with an increased relative risk of asthma in both adults [21, 23-26] and children [27-30]. A more limited body of evidence suggests that obesity may also increase the severity of asthma, as weight loss by various means resulted in improved disease control in several small series [31-35]. However, the present authors are unaware of any studies that have explored the possibility that obesity might
AFFILIATIONS

*Division of Pulmonary and Critical Care Medicine, University of Michigan, Ann Arbor, Ml, ${ }^{\#}$ Merck \& Co., Inc., Rahway, NJ, and 'Merck \& Co., Inc., West Point, PA, USA.

CORRESPONDENCE M. Peters-Golden 6301 MSRB III 1150 W. Medical Center Drive Ann Arbor Ml 48109-0642 USA

Fax: 17347644556 E-mail: petersm@med.umich.edu

Received:

July 012005

Accepted after revision:

November 042005

SUPPORT STATEMENT

The present study was funded by Merck \& Co. Inc., West Point, PA USA.

European Respiratory Journal Print ISSN 0903-1936 Online ISSN 1399-3003 
influence therapeutic responsiveness either to asthma medications or to the placebo itself.

Herein, the present authors have evaluated the relationship between body mass index (BMI) and measures of treatment response by performing a post hoc analysis of an established database from four previous placebo-controlled studies randomising 3,073 adults with moderate asthma to treatment with placebo, the anti-LT agent montelukast or the inhaled corticosteroid beclomethasone. The findings of the present study point to BMI as a previously unrecognised factor influencing the placebo response in asthma, and suggest the possibility that it may differentially influence responses to these two types of controller medications.

\section{METHODS}

\section{Study design}

Analyses were undertaken to provide evidence for differential efficacy of montelukast and inhaled beclomethasone in patients with differing BMI. The data used for the analyses were pooled from four multicentre, randomised, parallelgroup studies comparing montelukast, beclomethasone and placebo. The first two identically designed trials (studies one and two) had a 12-week, double-blind treatment period [3, 4]. The second pair of identically designed studies (studies three and four) had a 6-week, double-blind treatment period [5-6]. Pooling data from 6- and 12-week studies was thought to be justified because the maximum efficacy of the two active drugs is reached by 6 weeks, and efficacy was measured at 6 and 12 weeks in the longer duration studies and was found to be consistent. Nonetheless, all statistical models included protocol as a covariate to adjust for small differences among the studies.

The 3,073 eligible patients were randomly assigned, according to blinded allocation schedules produced by the study sponsor, to receive either montelukast sodium (10-mg tablet, q.d. in the evening), beclomethasone dipropionate (inhalation, $200 \mu \mathrm{g}$ (four puffs) b.i.d.), or placebo in a 3:2:2 (studies one and two) or a 3:3:1 patient ratio (studies three and four). Each patient received one tablet q.d. (active or matching placebo) and one inhaler dose b.i.d. (active or matching placebo) during the double-blind treatment periods.

\section{Inclusion criteria}

Inclusion criteria were identical for all four studies. Males and females aged $\geqslant 15$ yrs with a $\geqslant 1$-yr history of clinical symptoms of asthma were enrolled. Patients' asthma treatment could include only short-acting $\beta$-agonist (albuterol) at the time of randomisation. Only one of the four studies allowed inhaled steroids of any kind in addition to the randomised treatment, and only 155 subjects in the entire study were using inhaled steroids. Patients were eligible for randomisation if they had a forced expiratory volume in one second (FEV1) $>50 \%$ and $<85 \%$ of the predicted value at rest and at least a $15 \%$ increase in FEV1 after $\beta$-agonist administration (demonstrated twice) during the run-in period. In addition, all patients were required to have average $\beta$-agonist use greater than two puffs per day during the baseline run-in period. Eligible patients were nonsmokers for at least $1 \mathrm{yr}$ prior to enrolment, with a smoking history of no more than 7 pack-yrs.

\section{Evaluations}

Subjects completed daily diary cards throughout the doubleblind treatment periods for all studies. The daily diary cards collected information on asthma symptoms, asthma attacks (patient indicated Yes or No), night-time awakening and $\beta$ agonist use (puffs $\cdot$ day $^{-1}$ ). Spirometry was performed at every visit during double-blind therapy according to American Thoracic Society acceptability and reproducibility criteria using a standard spirometer. Patients were required to withhold the use of inhaled $\beta$-agonist for $6 \mathrm{~h}$ before the visit.

An asthma control day (ACD) was defined as a day with no more than two puffs $\beta$-agonist use (including those for exercise prophylaxis), no night-time awakenings and no asthma attacks. Nocturnal awakening was evaluated based on the patient's response to a single question with a four-point scale (no awakenings $=0$; one awakening $=1$; more than one awakening =2; awake all night=3). An asthma attack was defined as worsening asthma resulting in an unscheduled visit to the doctor's office or emergency department, hospitalisation or treatment with oral corticosteroids.

\section{Statistical methods}

The prespecified primary end point for this secondary pooled analysis of four studies was ACD, expressed as the proportion of days on study. This end point was chosen because it incorporates multiple aspects of asthma control. Secondary end points were percentage change in FEV1 (expressed in litres), percentage of nights with nocturnal awakenings and percentage change in $\beta$-agonist use (puffs $\cdot$ day $^{-1}$ ).

Height and weight were measured at the screening visit. Patients were classified into three groups based on their BMI, which were defined as follows: normal $\left(<25.0 \mathrm{~kg} \cdot \mathrm{m}^{-2}\right)$, overweight $\left(25-29.9 \mathrm{~kg} \cdot \mathrm{m}^{-2}\right)$ and obese $\left(\geqslant 30.0 \mathrm{~kg} \cdot \mathrm{m}^{-2}\right)$. A modified intention-to-treat approach was used that included all randomised patients with at least one on-treatment measurement. Statistical tests for each end point were performed using an ANCOVA model with factors for treatment, protocol, BMI and treatment-by-BMI interaction, and baseline FEV1 (\% predicted) as a covariate to adjust for treatment severity.

Analyses were performed using BMI as a three-category variable (normal, overweight and obese) and, because the overweight category appeared to behave similarly to the obese category, separate analyses were performed using a twocategory variable (normal versus overweight/obese). Additional analyses were performed using the same covariates, but with BMI as a continuous variable. All statistical comparisons were declared significant at $\mathrm{p}<0.05$, and interactions were declared statistically significant at $\mathrm{p}<0.10$.

Multivariable model fitting was used to explore the effect of covariates for each end point, using BMI as both a categorical and a continuous variable and evaluating the contribution of baseline covariates of age, sex, race (White versus other), FEV1 (\% pred) and $\beta$-agonist percentage reversibility to the model. Best models were selected using stepwise forward and backward selection procedures for model fitting.

\section{RESULTS}

\section{Demographics}

Table 1 summarises patient baseline demographics and characteristics by BMI category. Patients who were obese were 
TABLE 1 Baseline demographics and clinical characteristics by body mass index category

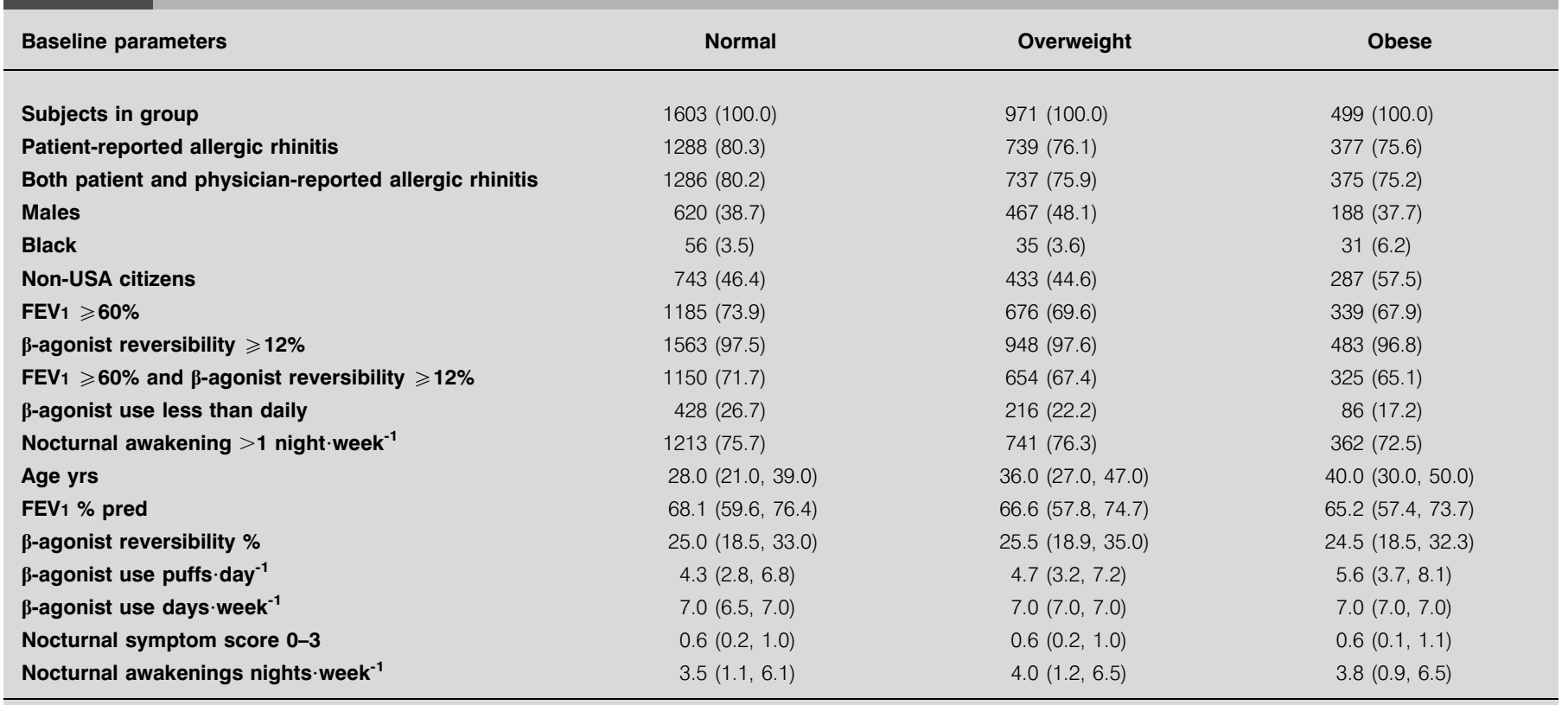

Data are presented as $n(\%)$ or median (lower quartile, upper quartile). FEV 1 : forced expiratory volume in one second; \% pred: percentage predicted.

older, with a median age of $40 \mathrm{yrs}$, compared with a median age of 36 yrs for overweight patients and a median age of 28 yrs for normal-weight patients. More than $80 \%$ of patients with normal weight had allergic rhinitis, compared with $76 \%$ who were overweight and obese. Of patients with normal weight, $74 \%$ had FEV1 $\geqslant 60 \%$ compared with $70 \%$ of patients who were overweight and $68 \%$ of patients who were obese. Median FEV1 \% pred was $68.1 \%$ for patients of normal weight, $66.6 \%$ for patients who were overweight and $65.2 \%$ for patients who were obese.

Approximately $52 \%$ of the patients in the total population were classified in the normal weight category (BMI $<25 \mathrm{~kg} \cdot \mathrm{m}^{-2}$ ), with $32 \%$ of patients classified as overweight $\left(25-29.9 \mathrm{~kg} \cdot \mathrm{m}^{-2}\right)$ and $16 \%$ of patients classified as obese (BMI $\geqslant 30.0 \mathrm{~kg} \cdot \mathrm{m}^{-2}$ ). A similar distribution of BMI was seen for each treatment group. Treatment groups were balanced for sex, race, age, BMI, FEV1 ( $\mathrm{L}$ and $\%$ pred) and $\beta$-agonist percentage reversibility across the three BMI categories (tables 2 and 3).

\section{Effect of BMI on asthma control days}

The analysis of ACD was performed by treatment group and by BMI category. Covariates in the model included protocol and baseline FEV1 (\% pred). Placebo patients in the normal BMI category had a higher percentage of ACD than patients who were overweight or obese $(33.91 \%$ compared with $25.04 \%$ for overweight, $\mathrm{p}=0.002 ; 25.80 \%$ for obese, $\mathrm{p}=0.026$ ).

The effect of montelukast on ACD was similar across all three BMI categories, but that of beclomethasone decreased with increasing BMI (fig. 1a). When considering the effect of the two therapies by BMI category, the mean placebo-adjusted (active value minus placebo value) percentage of ACD was significantly greater for beclomethasone than for montelukast in patients in the normal category (18.6 versus $9.5 \%, \mathrm{p}<0.001$ ), but not for those in the overweight (18.8 versus $15.7 \%, \mathrm{p}=0.248$ ) and obese categories (13.9 versus $13.4 \%, p=0.895$; fig. $1 b$ ). The $\mathrm{p}$-value for the interaction of BMI category by treatment group was 0.130 . Using the same end point of ACD analysing BMI in three categories, a multivariable model was fitted, adding all other baseline covariates to baseline FEV1 \% pred. In this model, age, race and baseline FEV1 remained significant covariates, but the estimated treatment effect changed only slightly from the original model $(18.7 \%$ for beclomethasone versus $9.6 \%$ for montelukast, 18.6 versus $15.5 \%$, and 14.3 versus $13.2 \%$ in the normal, overweight and obese categories, respectively.

The percentages of ACD were similar in the overweight and obese categories $(\mathrm{p}=0.847$ in the above model), justifying combining them into one category. When overweight and obese categories were combined and compared with the normal category, the p-value for the interaction of BMI category by treatment group was 0.044 , indicating that the treatment groups behaved differently within these two different groupings for BMI. In this two-category model, the percentage of ACD for the placebo arm was $33.89 \%$ in the normal group compared with $25.29 \%$ in the overweight/obese group $(\mathrm{p}<0.001)$.

ACD as a function of continuous BMI is summarised within each treatment group in figure 2 . These analyses confirmed the suggestion made by the categorical data described above that the treatment effect seen with montelukast was relatively constant across all BMI categories, but the effect with both beclomethasone and placebo decreased with increasing BMI. Clear differences exist between the three treatment groups in the relationship between BMI and ACD. A multivariable model was fitted with treatment, protocol, BMI and 
TABLE 2 Baseline demographics by body mass index (BMI) category and treatment group

\begin{tabular}{|c|c|c|c|c|}
\hline Variable & Patient status ${ }^{\#}$ & Montelukast & Beclomethasone & Placebo \\
\hline \multicolumn{5}{|l|}{ Sex } \\
\hline \multirow{2}{*}{ Female } & Overweight & $220(26.1)$ & $156(29.2)$ & $128(30.5)$ \\
\hline & Obese & $144(17.1)$ & $91(17.0)$ & 76 (18.1) \\
\hline Male & Normal & $279(46.9)$ & $175(48.6)$ & 166 (51.9) \\
\hline \multicolumn{5}{|l|}{ Race } \\
\hline \multirow[t]{3}{*}{ White } & Normal & $490(51.5)$ & $254(51.8)$ & 266 (53.1) \\
\hline & Overweight & $294(30.9)$ & $164(33.5)$ & $153(30.5)$ \\
\hline & Obese & 167 (17.6) & 72 (14.7) & 82 (16.4) \\
\hline Black & Normal & $28(49.1)$ & $14(43.7)$ & $14(42.4)$ \\
\hline Hispanic & Obese & $28(10.3)$ & $46(20.3)$ & $18(13.0)$ \\
\hline \multirow[t]{3}{*}{ Other } & Normal & $97(61.4)$ & $83(57.2)$ & $32(47.1)$ \\
\hline & Overweight & 40 (25.3) & 37 (25.5) & 27 (39.7) \\
\hline & Obese & 21 (13.3) & $25(17.2)$ & $9(13.2)$ \\
\hline \multicolumn{5}{|l|}{ Age yrs } \\
\hline & Normal & $31.3(15-79)$ & $31.6(15-81)$ & $31.6(15-77)$ \\
\hline & Overweight & $37.8(15-78)$ & $39.1(15-81)$ & $38.3(15-85$ \\
\hline & Obese & $41.7(15-75)$ & $39.9(16-73)$ & $40.7(15-81)$ \\
\hline
\end{tabular}

Data are presented as $\mathrm{n}(\%)$ or mean (range). ${ }^{\#}$ : Normal: BMI $<25.0 \mathrm{~kg} \cdot \mathrm{m}^{-2}$; overweight: $25-29.9 \mathrm{~kg} \cdot \mathrm{m}^{-2}$; obese: $\mathrm{BMl} \geqslant 30.0 \mathrm{~kg} \cdot \mathrm{m}^{-2}$

TABLE 3 Baseline clinical characteristics by body mass index (BMI) category and treatment group

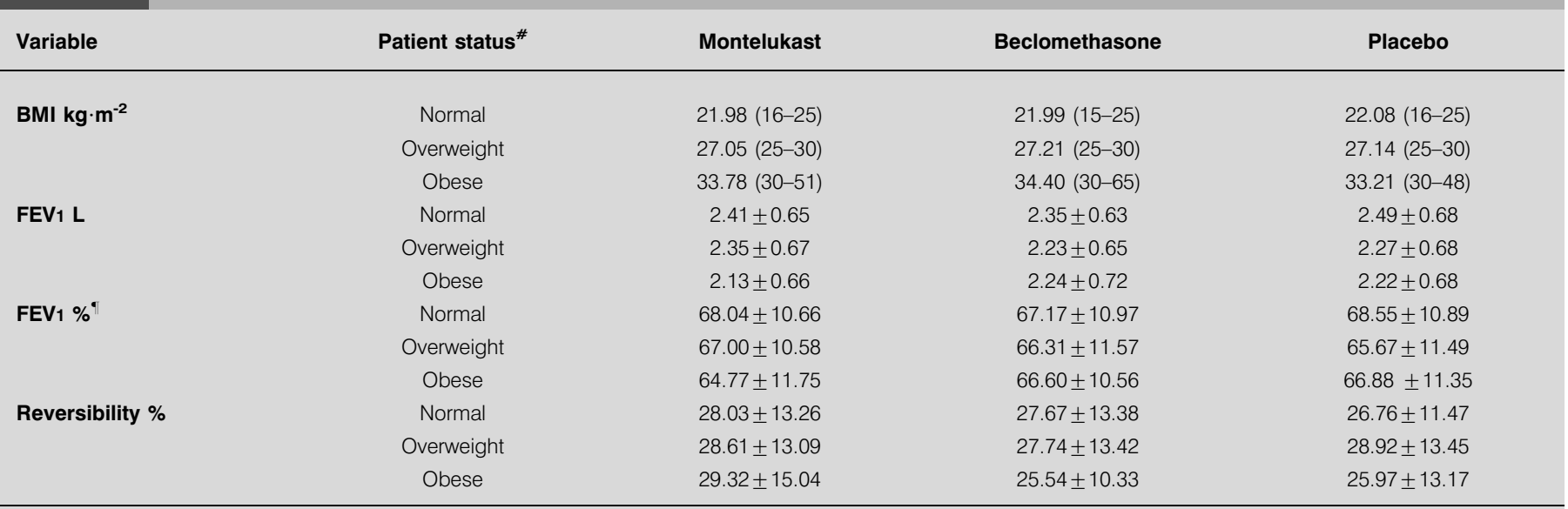

Data are presented as mean (range) or mean $\pm \mathrm{SD}$. FEV1: forced expiratory volume in one second; \% pred: percentage predicted. ${ }^{\#}:$ Normal: $\mathrm{BMI}<25.0 \mathrm{~kg} \cdot \mathrm{m}^{-2}$; overweight: $25-29.9 \mathrm{~kg} \cdot \mathrm{m}^{-2}$; obese: $\mathrm{BMl} \geqslant 30.0 \mathrm{~kg} \cdot \mathrm{m}^{-2}$. $:$ predicted mean $\pm \mathrm{SD}$.

treatment-by-BMI interaction as factors with baseline FEV1 $(\%$ pred) as a covariate, and is summarised in table 4 . The $R^{2}$ value for this regression was 0.107 , indicating that the included covariates were not sufficient to predict ACD. However, the pvalue for the interaction term of treatment group and BMI was 0.016 , indicating that there was a difference in the effect of the different treatments with BMI. The actual calculated slope for the regression line with montelukast $(-0.28)$ was not significant (95\% confidence interval (CI): $-0.66-0.10$, which includes 0 ), indicating that when adjustment was made for the other factors in the model, the efficacy of montelukast did not change with BMI. Both beclomethasone and placebo had significant slopes with BMI, -1.10 (95\% CI: $-1.54--0.66)$ and -0.87 (95\% CI: $-1.42--0.32)$, respectively. 

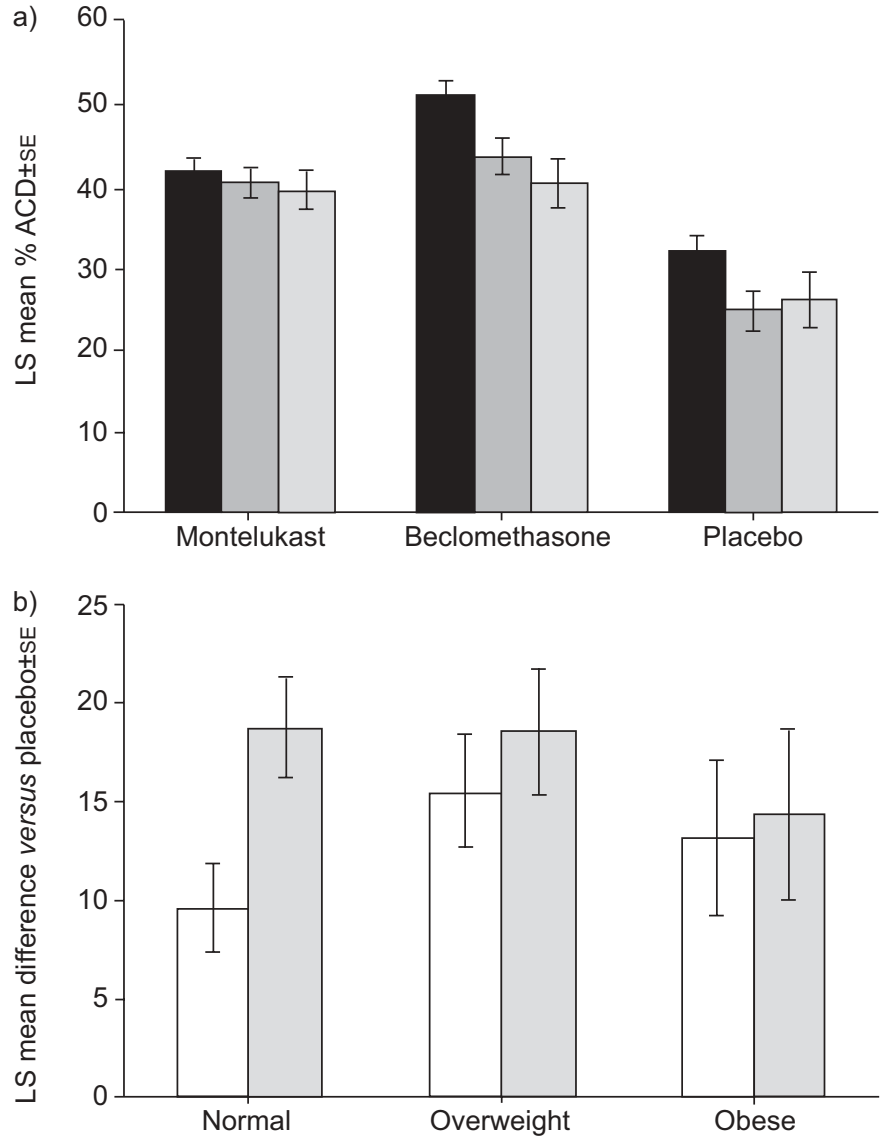

FIGURE 1. Bar graphs showing asthma control days (ACD) by treatment group. a) Least squares (LS) mean percentage of ACD for montelukast, beclomethasone and placebo divided into three body mass index (BMI) categories.

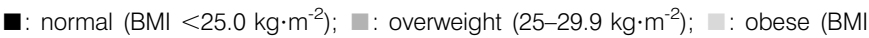
$\geqslant 30.0 \mathrm{~kg} \cdot \mathrm{m}^{-2}$ ). b) Placebo-adjusted (active value minus placebo value) LS mean ACD by BMl category for montelukast $(\square)$ and beclomethasone $(\square)$.

\section{Other efficacy end points}

Analyses also were conducted to examine if BMI had any effect on response to treatment for percentage change from baseline in FEV1, percentage of nights awake and percentage change from baseline in $\beta$-agonist use. For all of these end points, the response on the placebo arm for overweight and obese categories was less than the response for the normal category. The percentage change from baseline FEV1 was $4.66 \%$ (95\% CI: $2.99-6.33), 1.46(-0.65-3.57)$ and $0.50(-2.42,3.43)$ for the normal, overweight and obese categories, respectively. For the percentage of nights awake, the placebo response was $42.10 \%$ (38.77$45.44), 51.24(47.01-55.47)$ and $49.76(43.86-55.67)$ for the normal, overweight and obese categories, respectively. Finally, for the percentage change from baseline in $\beta$-agonist use, the placebo response was $9.58 \%$ (95\% CI: 4.88-14.27), 3.51 $(-2.45-9.48)$ and $4.91(-3.52-13.33)$ for the normal, overweight and obese categories.

For FEV1, the p-value for the interaction of BMI category by treatment group was 0.379 using the three categories for BMI, also indicating that there were no statistical differences for different groupings of BMI by treatment for this end point. For beclomethasone, the percentage change in FEV1 was $15.50 \%$ for

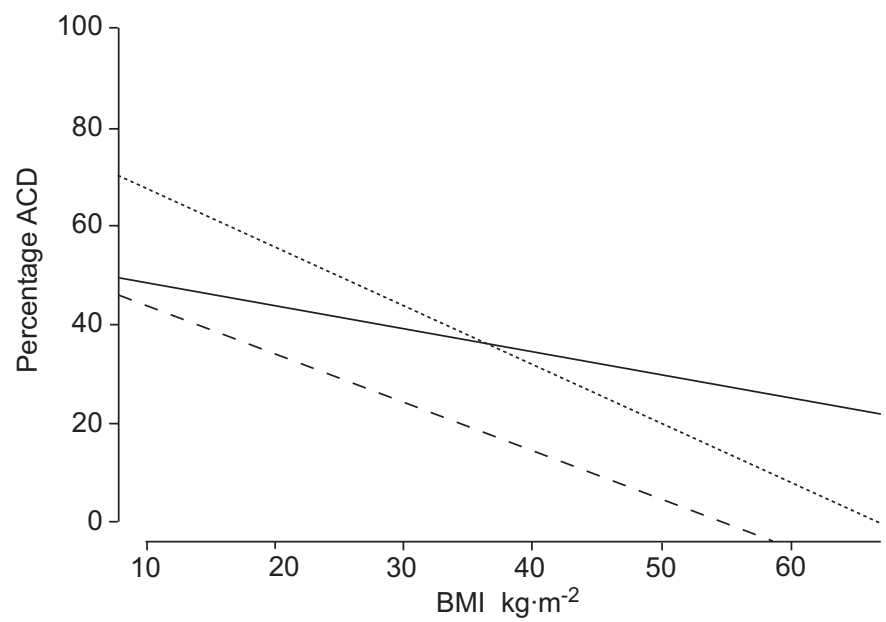

FIGURE 2. Regression analyses of asthma control days (ACD) by body mass index (BMI). Line graph showing the results of the regression analysis for placebo (-----), montelukast $(-)$ and beclomethasone $(\cdots \cdots \cdots)$. Equations are $\mathrm{ACD}=61.77-1.09 \times \mathrm{BMI}$ (placebo), $\mathrm{ACD}=54.57-0.36 \times \mathrm{BMI}$ (montelukast) and $\mathrm{ACD}=80.87-1.24 \times \mathrm{BMI}$ (beclomethasone).

the normal, $15.38 \%$ for the overweight and $12.13 \%$ for the obese category. For montelukast, the percentage change in FEV1 was $10.84 \%$ for normal, $10.26 \%$ for overweight and $8.95 \%$ for the obese category.

For the percentage of nights awake, the p-value for the interaction of BMI category by treatment group was 0.059 using the three categories for BMI, confirming the findings of statistically significant differences for the different groupings of BMI by treatment (defined as $p<0.10$ ). The percentage of nights awake was greater in the overweight and obese categories than in the normal group in both treatment groups. For beclomethasone, $26.19 \%$ for the normal BMI group compared with $30.76 \%$ for the overweight group and $28.55 \%$ for the obese group. For montelukast, $32.59 \%$ for the normal BMI group compared with $32.37 \%$ for the overweight group and $36.54 \%$ for the obese group.

For $\beta$-agonist use, the $\mathrm{p}$-value for the interaction of BMI category by treatment group was 0.429 using the three categories for BMI, indicating that there were no statistical differences for different groupings of BMI by treatment for this end point. For montelukast, the percentage improvement in $\beta$ agonist use was $29.5 \%$ for normal, $29.2 \%$ for overweight and $30.3 \%$ for the obese category. For beclomethasone, the percentage improvement was $41.3 \%$ for normal, $36.8 \%$ for overweight and $33.0 \%$ for the obese category.

Placebo-adjusted responses for beclomethasone and montelukast for the percentage change in FEV1, percentage of nights awake and percentage change in $\beta$-agonist use are shown in figure 3 .

\section{DISCUSSION}

An extensive body of literature has suggested that states of overweight and obesity represent an important risk factor for the development of asthma. However, information about the relationship between $\mathrm{BMI}$ and asthma control is limited to several small series of asthma patients studied before and after 


\begin{tabular}{|c|c|c|c|c|c|c|}
\hline Montelukast & $41.88 \pm 0.92$ & $-5.88(-8.95--2.81)$ & $12.10(8.98-15.23)$ & -0.28 & 0.146 & $(-0.66-0.10)$ \\
\hline Beclomethasone & $47.76 \pm 1.24$ & & $17.98(14.32-21.65)$ & -1.10 & $<0.0001$ & $(-1.54--0.66)$ \\
\hline
\end{tabular}

Data are presented as mean \pm SE or mean difference $(95 \%$ confidence interval $(\mathrm{CI}))$, unless otherwise stated. LS: least squares. The $p$-value for treatment by BMI interaction is 0.016 . LS mean \pm SE are estimated from the ANCOVA model including terms for treatment, protocol, BMI, treatment by BMI interaction, and baseline FEV1 percentage predicted. ${ }^{*}$ : the difference is the estimated difference of montelukast-beclomethasone; $"$ : the difference is the estimated difference of either montelukast or beclomethasone-placebo

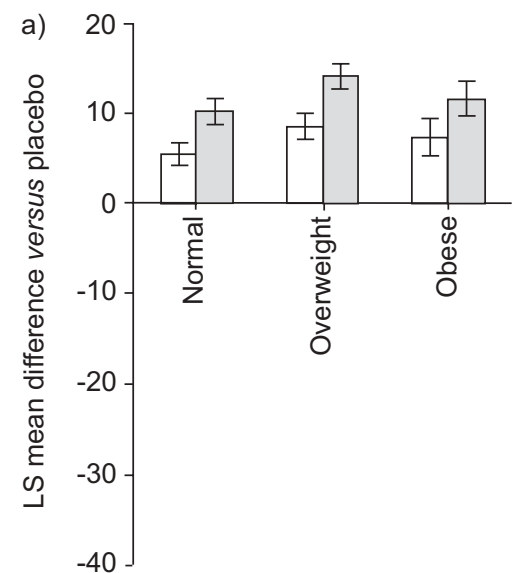

b)

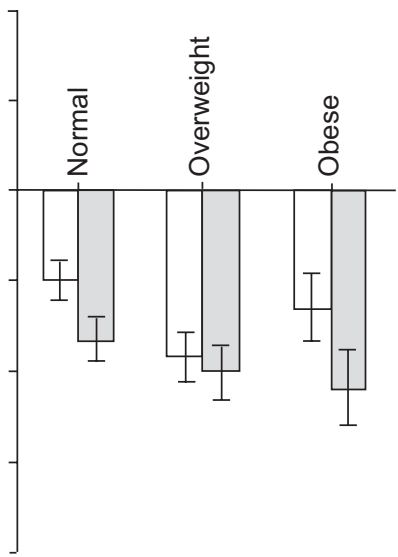

c)

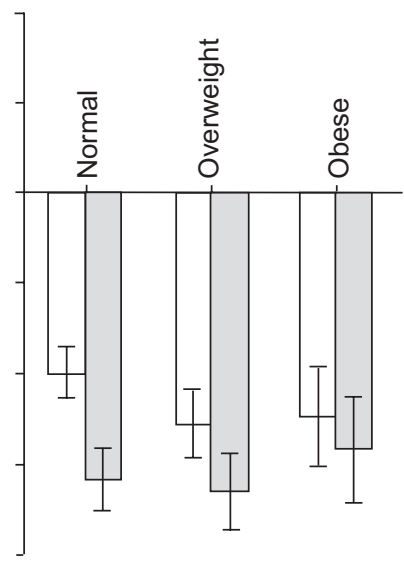

FIGURE 3. Placebo-adjusted responses for other efficacy end points by body mass index (BMI) group. Bar graphs showing placebo-adjusted (active value minus placebo value) least squares (LS) mean values for a) percentage change from baseline in forced expiratory volume in one second; b) the percentage of nights awake and c) percentage change from baseline in $\beta$-agonist use. $\square$ : montelukast; $\quad[$ : beclomethasone.

surgically induced or medically supervised weight loss. In this study, the present authors capitalised on an existing database of four registered trials in which more than 3,000 individuals with moderate asthma were randomised to treatment with placebo, inhaled beclomethasone or oral montelukast. In these trials, compliance with study medication was verified to exceed $90 \%$. This study provides two novel types of information. First, analysis of the placebo-treated patients demonstrates that increasing BMI adversely influences the natural history of asthma during the 6 or 12 weeks of follow-up care. Secondly, analysis of montelukast- and beclomethasonetreated patients suggests, for the first time, that BMI influences responsiveness to asthma therapy and may do so differentially for the two controller agents.

The diagnosis of asthma in study patients was established by documenting $a \geqslant 15 \%$ increase in FEV1 after $\beta$-agonist use on two separate occasions prior to entry. The presence of significant chronic obstructive lung disease in study patients was unlikely in view of their age (median age: $33 \mathrm{yrs}$ ) and the maximal permitted smoking history of 7 pack-yrs. At baseline, the patients under investigation had moderate asthma, as judged by abnormal FEV1, an average of rescue $\beta$-agonist use b.i.d. and nocturnal awakenings several nights per week.
Asthma severity at baseline was modestly, but significantly, greater for individuals in the overweight and obese groups, as shown by their lower FEV1 (\% pred) and greater daily use of $\beta$ agonist. As the presence of respiratory symptoms and impaired lung function in the obese may reflect processes other than asthma, such as mechanical restriction and deconditioning, it is important to note that the degree of $\beta$ agonist reversibility was equivalent across BMI strata; this objective parameter strongly suggests that what is being assessed in the higher BMI groups is indeed asthma. Another argument against mere increases in subjective discomfort with increasing BMI is the fact that the two active treatments showed different effects on ACD with increasing BMI.

Not surprisingly, patient age correlated with BMI; however, subsequent multivariable analyses determined that age did not account for the observed differences among the groups. The treatment groups were balanced for demographic characteristics, parameters of asthma control and lung function. Although approximately half of the study patients were classified, according to BMI, into the overweight or obese categories, the prevalence of obesity in the present study's population $(16 \%)$ actually underestimated the prevalence 
noted for the population of the USA as a whole (21\%) [21] and for individuals with current asthma (27\%) [36].

A modest improvement in lung function and asthma symptom scores is commonly observed in placebo-treated patients participating in controlled trials of asthma therapy. Such improvement is generally attributed to frequent health-care contacts, improved inhaler technique and increased awareness of factors such as asthma triggers. It was informative to examine the effects of BMI on the placebo response. Placebotreated patients in the overweight and obese categories exhibited a significantly lower percentage of ACD than those in the normal BMI category. The difference of $8.9 \%$ in ACD between the placebo-treated normal and overweight/obese categories represents $75 \%$ of the observed treatment difference between montelukast and placebo, using all the randomised patients from the four trials, and translates into an additional month per year of control for normal BMI patients when compared with overweight and obese patients. Furthermore, when BMI was assessed as a continuous variable, the percentage ACD for placebo-treated patients, adjusted for all the other factors in the model, and, therefore, adjusted for asthma severity, decreased with increasing BMI, with a statistically significant slope of -0.87 . In addition, the percentage of nights awake increased and improvements in FEV1 decreased with increasing BMI in the placebo group. Similarly, on-study improvement in the percentage of $\beta$-agonist used was smaller in the overweight and obese groups compared with the normal BMI group (3.51 and 4.91\%, respectively, compared with $9.58 \%$ ). Thus, slight differences in asthma severity across BMI groups that were present at baseline became magnified during the follow-up interval. In some [26, 37, 38], but not all $[27,30]$, studies, the link between obesity and asthma prevalence was particularly evident in females, and a similar sex-specific relationship with BMI has been reported for asthma severity [39]. However, in the present study population, sex was not a significant covariate in the multivariable analyses. As it is axiomatic that responses to active asthma medications must be corrected for placebo responses, the hitherto unappreciated fact that placebo responses may themselves be influenced by BMI has important implications for the design and interpretation of asthma treatment trials.

As was seen with placebo, the percentage of ACD also significantly decreased with increasing BMI in those patients treated with beclomethasone. This was observed with both categorical and continuous analyses. When adjusted for placebo responses, the percentage of $\mathrm{ACD}$ and other end points with beclomethasone treatment were not significantly influenced by BMI. These data suggest that although responses to beclomethasone decrease with increasing BMI, the incremental improvement over placebo (which also decreases with increasing BMI) remains relatively constant.

The influence of BMI on responses to montelukast was fundamentally different from that observed for placebo or beclomethasone. Improvements in the percentage of ACD with montelukast did not significantly decrease with increasing BMI, either in categorical or continuous analyses. However, because the percentage of ACD decreases with increasing BMI when taking placebo, the placebo-adjusted benefit from montelukast actually increased with increasing BMI.
Although both active treatment agents were beneficial relative to placebo in all BMI categories, the benefits of montelukast versus beclomethasone relative to placebo were seen to vary with BMI. At normal BMI, beclomethasone was significantly superior to montelukast in the percentage of ACD; however, the difference narrowed and was not statistically significant in overweight individuals, and there was virtually no difference in the percentage of ACD in the obese. Multivariable analyses confirmed that the influence of BMI on treatment responses persisted, even in the presence of other variables known to impact asthma control.

These results provide possible new insights into the heterogeneity of therapeutic responses to asthma controller agents. However, it must be emphasised that the present investigation used post hoc or secondary analyses performed on data obtained from previous clinical trials. As such, the questions addressed are exploratory in nature, and the findings should merely be considered as hypothesis generating. Subsequent prospective studies will be necessary to determine if BMI is a relevant consideration in choosing between the inhaled corticosteroid and anti-LT classes of asthma controllers. Along with recent data demonstrating that smoking status is an important determinant of asthmatics' responses to inhaled [19] and systemic [40] corticosteroids, the present results with BMI emphasise the importance that simple acquired factors, distinct from genetic factors, might have in influencing therapeutic responses to pharmacological agents. Of course, it is likely that multiple genetic and acquired factors contribute and indeed interact with each other in determining such responses.

LTs comprise only one of a myriad of classes of mediators of asthmatic inflammation and bronchospasm. The fact that therapeutic responses to montelukast appeared to increase with increasing BMI suggests that asthma in the overweight and the obese may be a more LT-driven form of asthma than in individuals of normal BMI. This could potentially be explained by the previous demonstration [41, 42] that LT biosynthetic capacity and expression of enzymes in the LT biosynthetic pathway can be upregulated in vitro and in vivo by leptin, an adipocyte-derived hormone whose serum levels parallel total body fat mass [43, 44] and that has been increasingly implicated as a mediator of inflammation [45] and immune responses [46], as well as atopic asthma [47]. It can be speculated that leptin may provide a link between increasing $\mathrm{BMI}$ and the relative importance of LTs as mediators driving asthma. It must be emphasised, however, that LT levels were not measured in cells or relevant body fluids of study patients, and other mechanisms might explain the relationship between BMI and responsiveness to therapy. Certainly, confirmation of the effect of BMI on responsiveness to other drugs that inhibit LT synthesis or receptors would strengthen the likelihood that the present study's data reflect a specific mechanistic link between LTs and asthma in the obese. It is increasingly recognised that obesity results in a state of systemic inflammation $[48,49]$. However, the fact that increasing BMI did not confer a similar increase in responsiveness to beclomethasone suggests that the increased asthmatic inflammation that exists in the overweight/obese may be relatively corticosteroidresistant. Whether such corticosteroid resistance might be explained, for example, by a more neutrophilic form of airway 
inflammation in the obese remains to be determined. However, it is noteworthy that a significant body of literature suggests that LT synthesis in human asthmatics is refractory to corticosteroids [50].

Several limitations of the present study must be acknowledged. First, as noted above, it used a post hoc analysis; although a prospective evaluation would have been preferable, the three treatment groups were balanced for BMI distribution as well as other variables. Despite their limitations, there is an important place for secondary analyses within the context of the analysis of data from clinical trials. Secondly, although a substantial proportion of Hispanic patients were represented, the study population contained few Black patients. Therefore, it may not be possible to generalise results to this population. Thirdly, the order of magnitude of the observed differences were small and may not be clinically significant; however, they do indicate a trend, and the concept is worthy of being tested prospectively in future studies. In addition, it is evident that the relation between BMI and the percentage of ACD in the montelukast group was stronger than that between BMI and FEV1. There is ample precedent for dissociations among various outcome measures and for FEV1 in particular $[1,5]$.

Three important conclusions emerge from the present study. First, these data suggest, for the first time, that body mass index influences placebo responses in asthma. Secondly, body mass index is an important determinant of response to active treatment and warrants consideration in future studies. Thirdly, differences in responsiveness to montelukast and beclomethasone by body mass index may be important in considering treatment choices in individual adult asthmatics. A differential impact on responses to montelukast versus beclomethasone may provide clues into the mechanisms by which obesity modulates asthmatic inflammation.

\section{ACKNOWLEDGEMENTS}

The authors would like to thank J. Pawlowski for help with manuscript preparation.

\section{REFERENCES}

1 Peters SP. Heterogeneity in the pathology and treatment of asthma. Am J Med 2003; 115: Suppl. 3A, 49S-54S.

2 Drazen J, Silverman E, Lee T. Heterogeneity of therapeutic responses in asthma. Br Med Bull 2000; 56: 1054-1070.

3 Malmstrom K, Rodriguez-Gomez G, Guerra J, et al. Oral montelukast, inhaled beclomethasone, and placebo for chronic asthma. Ann Intern Med 1999; 130: 487-495.

4 Reiss T, Chervinsky P, Dockhorn R, Shingo S, Seidenberg B, Edwards T. Montelukast, a once-daily leukotriene receptor antagonist, in the treatment of chronic asthma: a multicenter, randomized, double-blind trial. Arch Intern Med 1998; 158: 1213-1220.

5 Israel E, Chervinsky PS, Friedman B, et al. Effects of montelukast and beclomethasone on airway function and asthma control. J Allergy Clin Immunol 2002; 110: 847-854.

6 Baumgartner RA, Martinez G, Edelman JM, et al. Montelukast Asthma Study Group. Distribution of therapeutic response in asthma control between oral montelukast and inhaled beclomethasone. Eur Respir J 2003; 21: 123-128.
7 Szefler SJ, Martin RJ, King TS, et al. Asthma Clinical Research Network of the National Heart Lung, and Blood Institute. Significant variability in response to inhaled corticosteroids for persistent asthma. J Allergy Clin Immunol 2002; 109: 410-418.

8 Strauss L, Hejal R, Galan G, Dixon L, McFadden ER Jr. Observations on the effects of aerosolized albuterol in acute asthma. Am J Respir Crit Care Med 1997; 155: 454-458.

9 Palmer LJ, Silverman ES, Weiss ST, Drazen JM. Pharmacogenetics of asthma. Am J Respir Crit Care Med 2002; 165: 861-866.

10 In K, Asano K, Beier D, et al. Naturally occurring mutations in the human 5-lipoxygenase gene promoter that modify transcription factor binding and reporter gene transcription. J Clin Invest 1997; 99: 1130-1137.

11 Sanak M, Simon HU, Szczeklik A. Leukotriene C4 synthase promoter polymorphism and risk of aspirin-induced asthma. Lancet 1997; 350: 1599-1600.

12 Pillai SG, Cousens DJ, Barnes AA, et al. Investigators of the GAIN Network. A coding polymorphism in the CYSLT2 receptor with reduced affinity to LTD4 is associated with asthma. Pharmacogenetics 2004; 14: 627-633.

13 Leung DY, Hamid Q, Vottero A, et al. Association of glucocorticoid insensitivity with increased expression of glucocorticoid receptor beta. J Exp Med 1997; 186: 1567-1574.

14 Drazen J, Yandava C, Dube L, et al. Pharmacogenetic association between ALOX5 promoter genotype and the response to anti-asthma treatment. Nat Genet 1999; 22: 168-170.

15 Currie GP, Lima JJ, Sylvester JE, Lee DK, Cockburn WJ, Lipworth BJ. Leukotriene C4 synthase polymorphisms and responsiveness to leukotriene antagonists in asthma. $\mathrm{Br} \mathrm{J}$ Clin Pharmacol 2003; 56: 422-426.

16 Gagliardo R, Vignola AM, Mathieu M. Is there a role for glucocorticoid receptor beta in asthma? Respir Res 2001; 2: $1-4$.

17 Fowler SJ, Hall IP, Wilson AM, Wheatley AP, Lipworth BJ. 5-Lipoxygenase polymorphism and in-vivo response to leukotriene receptor antagonists. Eur J Clin Pharmacol 2002; 58: 187-190.

18 Sampson A, Siddiqui S, Buchanan D, et al. Variant LTC4 synthase allele modifies cysteinyl leukotriene synthesis in eosinophils and predicts clinical response to zafirlukast. Thorax 2000; 55: Suppl. 2, S28-S31.

19 Chalmers GW, Macleod KJ, Little SA, Thomson LJ, McSharry CP, Thomson NC. Influence of cigarette smoking on inhaled corticosteroid treatment in mild asthma. Thorax 2002; 57: 226-230.

20 Weiss ST. Epidemiology and heterogeneity of asthma. Ann Allergy Asthma Immunol 2001; 87: Suppl. 1, 5-8.

21 Mokdad AH, Ford ES, Bowman BA, et al. Prevalence of obesity, diabetes, and obesity-related health risk factors, 2001. JAMA 2003; 289: 76-79.

22 Weiss S, Shore S. Obesity and asthma: directions for research. Am J Respir Crit Care Med 2004; 169: 963-968.

23 Camargo CA Jr, Weiss ST, Zhang S, Willett WC, Speizer FE. Prospective study of body mass index, weight change, and risk of adult-onset asthma in women. Arch Intern Med 1999; 159: 2582-2588. 
24 Chen $\mathrm{Y}$, Dales R, Krewski D, Breithaupt K. Increased effects of smoking and obesity on asthma among female Canadians: the National Population Health Survey, 19941995. Am J Epidemiol 1999; 150: 255-262.

25 Young SY, Gunzenhauser JD, Malone KE, McTiernan A. Body mass index and asthma in the military population of the northwestern United States. Arch Intern Med 2001; 161: 1605-1611.

26 Guerra S, Sherrill DL, Bobadilla A, Martinez FD, Barbee RA. The relation of body mass index to asthma, chronic bronchitis, and emphysema. Chest 2002; 122: 1256-1263.

27 von Mutius E, Schwartz J, Neas LM, Dockery D, Weiss ST. Relation of body mass index to asthma and atopy in children: the National Health and Nutrition Examination Study III. Thorax 2001; 56: 835-838.

28 Gennuso J, Epstein LH, Paluch RA, Cerny F. The relationship between asthma and obesity in urban minority children and adolescents. Arch Pediatr Adolesc Med 1998; 152: 1197-1200.

29 Rodriguez MA, Winkleby MA, Ahn D, Sundquist J, Kraemer HC. Identification of population subgroups of children and adolescents with high asthma prevalence: findings from the Third National Health and Nutrition Examination Survey. Arch Pediatr Adolesc Med 2002; 156 269-275.

30 Gilliland FD, Berhane K, Islam T, et al. Obesity and the risk of newly diagnosed asthma in school-age children. Am J Epidemiol 2003; 158: 406-415.

31 Dixon JB, Chapman L, O'Brien P. Marked improvement in asthma after Lap-Band surgery for morbid obesity. Obes Surg 1999; 9: 385-389.

32 Stenius-Aarniala B, Poussa T, Kvarnstrom J, Gronlund EL, Ylikahri M, Mustajoki P. Immediate and long term effects of weight reduction in obese people with asthma: randomised controlled study. BMJ 2000; 320: 827-832.

33 Aaron SD, Fergusson D, Dent R, Chen Y, Vandemheen KL, Dales RE. Effect of weight reduction on respiratory function and airway reactivity in obese women. Chest 2004; 125: 2046-2052.

34 Hakala K, Stenius-Aarniala B, Sovijarvi A. Effects of weight loss on peak flow variability, airways obstruction, and lung volumes in obese patients with asthma. Chest 2000; 118: 1315-1321.

35 Macgregor A, Greenberg R. Effect of surgically induced weight loss on asthma in the morbidly obese. Obes Surg 1993; 3: 15-21.

36 Ford ES, Mannino DM, Redd SC, Mokdad AH, Galuska DA, Serdula MK. Weight-loss practices and asthma: findings from the behavioral risk factor surveillance system. Obes Res 2003; 11: 81-86.

37 Chen Y, Dales R, Tang M, Krewski D. Obesity may increase the incidence of asthma in women but not in men: longitudinal observations from the Canadian National Population Health Surveys. Am J Epidemiol 2002; 155: 191-197.

38 Kim S, Camargo CA Jr. Sex-race differences in the relationship between obesity and asthma: the behavioral risk factor surveillance system, 2000. Ann Epidemiol 2003; 13: 666-673.

39 Varraso R, Siroux V, Maccario J, Pin I, Kauffmann F. Epidemiological study on the genetics and environment of asthma. Asthma severity is associated with body mass index and early menarche in women. Am J Respir Crit Care Med 2005; 171: 334-339.

40 Chaudhuri R, Livingston E, McMahon AD, Thomson L, Borland W, Thomson NC. Cigarette smoking impairs the therapeutic response to oral corticosteroids in chronic asthma. Am J Respir Crit Care Med 2003; 168: 1308-1311.

41 Mancuso P, Gottschalk A, Phare SM, et al. Leptin-deficient mice exhibit impaired host defense in Gram-negative pneumonia. J Immunol 2002; 168: 4018-4024.

42 Mancuso P, Gottschalk A, Phare SM, Peters-Golden M, Lukacs NW, Huffnagle GB. Leptin augments alveolar macrophage leukotriene synthesis by increasing phospholipase activity and enhancing group IVC iPLA2 (cPLA2gamma) protein expression. Am J Physiol Lung Cell Mol Physiol 2004; 287: L497-L502.

43 Maffei M, Halaas J, Ravussin E, et al. Leptin levels in human and rodent: measurement of plasma leptin and of RNA in obese and weight-reduced subjects. Nat Med 1995; 1: 1155-1161.

44 Chow VT, Phoon MC. Measurement of serum leptin concentrations in university undergraduates by competitive ELISA reveals correlations with body mass index and sex. Adv Physiol Educ 2003; 27: 70-77.

45 Loffreda S, Yang SQ, Lin HZ, et al. Leptin regulates proinflammatory immune responses. FASEB J 1998; 12: 57-65.

46 Matarese G, Moschos S, Mantzoros CS. Leptin in immunology. J Immunol 2005; 174: 3137-3142.

47 Guler N, Kirerleri E, Ones U, Tamay Z, Salmayenli N, Darendeliler F. Leptin does it have any role in childhood asthma? J Allergy Clin Immunol. 2004; 114: 254-259.

48 Lyon CJ, Law RE, Hsueh WA. Mini review: adiposity, inflammation, and atherogenesis. Endocrinology 2003; 144: 2195-2200.

49 Visser M, Bouter LM, McQuillan GM, Wener MH, Harris TB. Elevated C-reactive protein levels in overweight and obese adults. JAMA 1999; 282: 2131-2135.

50 Peters-Golden M, Sampson AP. Cysteinyl leukotriene interactions with other mediators and with glucocorticosteroids during airway inflammation. J Allergy Clin Immunol 2003; 111: Suppl. 1, S37-S48. 